\title{
Kinetic analysis of color changes in keyaki (Zelkova serrata) and sugi (Cryptomeria japonica) wood during heat treatment
}

\author{
Miyuki Matsuo $\cdot$ Kenji Umemura $\cdot$ Shuichi Kawai
}

Received: 22 July 2013/Accepted: 9 September 2013/Published online: 27 September 2013

(C) The Japan Wood Research Society 2013

\begin{abstract}
The kinetics of color changes in keyaki (Zelkova serrata Makino) and sugi (Cryptomeria japonica D. Don) wood during heat treatment were examined. The color of wood specimens treated at 90, 120, 150, and $180^{\circ} \mathrm{C}$ was measured by an imaging spectrophotometer and expressed using CIELAB color parameters. At any treatment temperature, values for $L^{*}$ and $\Delta E_{a b}^{*}$ decreased and increased in both wood species, respectively, with increased treatment time. Changes in $a^{*}$ and $b^{*}$ varied depending on wood species and treatment temperature. The color changes were successfully analyzed using the kinetic approach applying time-temperature superposition method. This approach elucidated and accurately predicted color changes during heat treatment.
\end{abstract}

Keywords Heat treatment - Color · Kinetic analysis . Keyaki (Zelkova serrata Makino) · Sugi (Cryptomeria japonica D. Don)

A part of this work was presented at the $62 \mathrm{nd}$ annual meeting of the Japan Wood Research Society, 2012.

M. Matsuo (ه)

Graduate School of Bioagricultural Sciences, Nagoya

University, Furo-cho, Chikusa-ku, Nagoya, Aichi 464-8601,

Japan

e-mail: miyuki@agr.nagoya-u.ac.jp

K. Umemura

Research Institute for Sustainable Humanosphere,

Kyoto University, Uji, Japan

S. Kawai

Graduate School of Advanced Integrated Studies in Human

Survivability, Kyoto University, Kyoto, Japan

\section{Introduction}

Heat treatment of wood, particularly at temperatures below the thermal decomposition point of each wood component, has been widely studied for various purposes, including wood modification, wood drying, and accelerated aging [1, 2]. Among the various properties of wood, color change during heat treatment has been frequently examined to develop chemical-free coloration methods [3] or to prevent staining and discoloration of wood during heating $[4,5]$ because color is esthetically important and affects the commercial value of wood. Many previous studies examined the effects of factors affected by heating processes such as temperature, duration, and moisture. However, individual phenomena in specific treatment conditions were described; no comprehensive study has been conducted to examine the color change behavior of wood during heat treatment. Color has also been studied as a nondestructive criterion for monitoring changes in other wood properties of wood. Previous studies investigated treatment duration and temperature within a limited range and for only a few wood species. Thus, the potential of color as a criterion remains to be determined. Some researchers found clear relationships between color and changes in other properties such as weight and mechanical properties during heat treatment [6-8], whereas others asserted that color is not suitable as a criterion for wood evaluation purposes, or that assessment techniques must be improved because results obtained in previous studies were unclear or occasionally contradictory [9-11].

In our previous studies $[12,13]$, color changes in hinoki wood (Chamaecyparis obtusa Endl.) and cellulose filter paper as a major component of wood were successfully analyzed using a kinetic approach, which allowed precise prediction of color changes at any temperature and time within the experimental ranges. Furthermore, the obtained 
results of hinoki wood were expanded to elucidate color changes during natural aging [14], leading to the conclusion that a uniform reaction (thermal oxidation) causes color changes during both natural aging and heat treatment.

In the present study, color changes in keyaki (Zelkova serrata Makino) and sugi (Cryptomeria japonica D. Don) were comprehensively investigated. These typical examples of hardwood and softwood, respectively, are widely used in wooden buildings in Japan, such as hinoki wood. Specimens were heat-treated at various treatment durations and temperatures. A kinetic approach was used to analyze the temperature dependency of color changes in these two species. The results were then compared with those of hinoki wood and cellulose filter paper to elucidate changes in the color of wood during heat treatment.

\section{Materials and methods}

Samples

A 100-year-old keyaki and a 180-year-old sugi tree were used. The trees were harvested in Japan and the wood was dried for more than 7 years under ambient room temperature conditions. A sample block of homogenous grain for each species was carefully selected from the area near the outermost part of the heartwood. The size of specimens was $60 \mathrm{~mm}$ (longitudinal direction) $\times 10 \mathrm{~mm}$ (radial direction) $\times 2 \mathrm{~mm}$ (tangential direction). Air-dried density and annual ring width of each species are summarized in Table 1. The specimens were dried in an air-circulating oven and a vacuum oven at $60{ }^{\circ} \mathrm{C}$ for $24 \mathrm{~h}$ each. Then, the specimens were heated in an air-circulating oven at 90, 120, 150, and $180{ }^{\circ} \mathrm{C}$ for durations ranging from $10 \mathrm{~min}$ to approximately 1.4 years (Table 2). Heating times were selected on the assumption that a $10{ }^{\circ} \mathrm{C}$ increase in reaction temperature halves the reaction rate, to obtain a similar degree of reaction intensity despite the differences in temperature [15].

\section{Color measurement}

Despite careful selection of samples, the density varied more widely and the annual ring width were larger than

Table 1 The average air-dried density and annual ring width with their standard deviations in parentheses

\begin{tabular}{llll}
\hline Sample & $\begin{array}{l}\text { Air dried density } \\
\left(\mathrm{g} / \mathrm{cm}^{3}\right)\end{array}$ & $\begin{array}{l}\text { Annual ring } \\
\text { width }(\mathrm{mm})\end{array}$ & $n$ \\
\hline Keyaki wood & $0.66(0.02)$ & $4.40(1.35)$ & 255 \\
Sugi wood & $0.36(0.02)$ & $1.50(0.31)$ & 243 \\
\hline
\end{tabular}

$n$ is the number of specimens used to calculate the average value
Table 2 Treatment temperature and time for keyaki and sugi wood

\begin{tabular}{ccccc}
\hline & $90{ }^{\circ} \mathrm{C}$ & $120^{\circ} \mathrm{C}$ & $150{ }^{\circ} \mathrm{C}$ & $180{ }^{\circ} \mathrm{C}$ \\
\hline Treatment time (h) & 12 & 1 & $40 \mathrm{~min}$ & \\
& & 3 & & \\
& 85.3 & 10.7 & 1.33 & $10 \mathrm{~min}$ \\
& 171 & 21.3 & 2.67 & $20 \mathrm{~min}$ \\
& 256 & 32 & 4 & $30 \mathrm{~min}$ \\
& 384 & 48 & 6 & \\
524 & 64 & 8 & 1 \\
& & & & 1.5 \\
& 1024 & 124 & 16 & 2 \\
& 3072 & 384 & 48 & 6 \\
6144 & 768 & 96 & 12 \\
9266 & & & \\
12288 & 1536 & 192 & 24 \\
& 3136 & 384 & 48 \\
& 5440 & & 84 \\
& 7680 & 960 & 120 \\
\hline
\end{tabular}

those of hinoki wood used in our previous study [12]. To reduce within-specimen variations in color caused by less homogeneity in tissue structure, specimen color was measured with a spectroscopic imaging system. The system consisted of an imaging spectrophotometer (ImSpector V8E, JFE Techno-Research Corporation, Tokyo, Japan), a monochrome camera with a charge-coupled device, xenon light source, stepper table, and controlling computer. This system provided scanned digital images of all specimens. Each pixel in the images contains spectroscopic intensity data, which can be converted to various color parameters using spectrum-analyzing software (ImSpector Spectrum Analyser, JFE Techno-Research Corporation, Tokyo, Japan). An area of $50 \mathrm{~mm}$ (longitudinal direction) $\times 8 \mathrm{~mm}$ (radial direction) in each specimen was scanned at a scanning resolution of approximately $0.19 \mathrm{~mm} /$ pixel (134 dpi). The color value of each specimen was calculated as the average of all pixels in the measured area, which reduced the variations in color.

The CIELAB color parameters $\left(L^{*}, a^{*}\right.$, and $\left.b^{*}\right)$ were used to express color changes. The differences in parameters $\Delta L^{*}, \Delta a^{*}$, and $\Delta b^{*}$ and the total color differences $\Delta E_{a b}^{*}$ were calculated using the following formulae [16, 17]:

$$
\begin{aligned}
\Delta L^{*} & =L^{*}-L_{0}^{*} \\
\Delta a^{*} & =a^{*}-a_{0}^{*} \\
\Delta b^{*} & =b^{*}-b_{0}^{*} \\
\Delta E_{a b}^{*} & =\sqrt{\Delta L *^{2}+\Delta a *^{2}+\Delta b *^{2}}
\end{aligned}
$$


Table 3 The average initial color values $L_{0}^{*}, a_{0}^{*}$, and $b_{0}^{*}$ with their standard deviations in parentheses

\begin{tabular}{llllr}
\hline Sample & $L_{0}^{*}$ & $a_{0}^{*}$ & $b_{0}^{*}$ & \multicolumn{1}{c}{$n$} \\
\hline Keyaki wood & $59.69(1.78)$ & $11.79(0.88)$ & $31.96(0.98)$ & 155 \\
Sugi wood & $56.25(2.43)$ & $11.63(1.02)$ & $21.27(1.03)$ & 90 \\
\hline
\end{tabular}

$n$ is the number of specimens used to calculate the average value

where $L^{*}$ is the lightness and $a^{*}$ and $b^{*}$ are the color coordinates under any treatment condition, respectively, and $L_{0}^{*}, a_{0}^{*}$, and $b_{0}^{*}$ are the corresponding initial values obtained as the average of untreated specimens. The values of $L_{0}^{*}, a_{0}^{*}$, and $b_{0}^{*}$ are summarized in Table 3. Four to five specimens were tested under each treatment condition and their average values and standard deviations calculated.

Kinetic analysis

A chemical reaction in a uniform phase can be described by the Arrhenius equation:

$k=A \exp \left(-\frac{E_{\mathrm{a}}}{R T}\right)$

where $k$ is the reaction rate constant, $A$ is the frequency factor, $E_{\mathrm{a}}$ is the apparent activation energy, $R$ is the gas constant, and $T$ is the absolute temperature at which the reaction occurs. In general, the temperature dependence of the reaction rate is expressed as $E_{\mathrm{a}}$. When changes in material properties were measured at different $T$, the values of $k$ were obtained from their reaction rates. By plotting the logarithm of $k$ versus the reciprocal of $T$, the values of $E_{\mathrm{a}}$ can be obtained from the slope of the regression line for the plots, which is called the Arrhenius plot [18]. Interpolating or extrapolating the regression line of the Arrhenius plot allows us to determine the reaction rate at any given temperature, which is useful not only in understanding the reaction, but also in predicting changes in the property under any conditions.

To determine the activation energy more accurately, a time-temperature superposition (TTSP) method has frequently been used for polymeric materials [19-22]. An Arrhenius approach applying the TTSP method is briefly described as follows. When changes in material properties at different treatment temperatures are plotted as functions of logarithmic treatment time and the plotted curves show a similar shape irrespective of treatment temperature, the plotted curves can be superposed to a single curve at a fixed reference temperature $T_{\text {ref }}$ along the logarithmic time axis. This shift distance used to superpose the curves is called the time-temperature shift factor $a_{T}$ and is given as follows:
$a_{T}=\frac{t_{T}}{t_{\mathrm{ref}}}$

where $t_{\text {ref }}$ is the treatment time at $T_{\text {ref }}$, and $t_{T}$ is the time required to obtain the same response at treatment temperature $T$. Combining Eqs. (3) and (4) thus gives:

$a_{T}=\exp \left[\frac{E_{\mathrm{a}}}{R}\left(\frac{1}{T}-\frac{1}{T_{\text {ref }}}\right)\right]$

where both $T$ and $T_{\text {ref }}$ are absolute temperatures. Plotting the logarithm of $a_{T}$ versus the reciprocal of $T$ is another way to calculate $E_{\mathrm{a}}$. Ding et al. [23] compared the TTSP method with the conventional method in Eq. (3) by analyzing several sets of data for cellulose degradation from literature. They concluded that the TTSP method is more accurate than the conventional one. In our previous study, the color changes of hinoki wood [12] and cellulose filter paper [13] were successfully analyzed using a combination of kinetic analysis and TTSP.

Though the curves plotted as a function of logarithmic treatment time are similar in shape, these curves cannot always be completely superposed, namely, a single smooth curve cannot be obtained only by a horizontal shift of data along the logarithmic time axis. In such cases, in addition to a horizontal shift, the data set may be shifted vertically along the logarithmic property axis to obtain a smooth superposed curve. This shift distance is called vertical shift factor $b_{T}$. Vertical shift has been used to explain the influences of temperature on the viscoelastic behaviors of thermorheologically complex materials [24-26]. Though application of $b_{T}$ in the context of color changes during heat treatment has not been attempted, the TTSP method was modified in the present study using $b_{T}$ formulated as follows:

$b_{T}=\frac{P_{T}}{P_{\text {ref }}}$

where $b_{T}$ is the vertical shift factor at treatment temperature $T, P_{T}$ the property at $T$, and $P_{\text {ref }}$ the property at $T_{\text {ref }}$.

To calculate $a_{T}$ and $b_{T}$, a temperature of $180{ }^{\circ} \mathrm{C}$ was chosen as $T_{\text {ref }}$. Nonlinear regressions were performed to find the best models that fitted well to changes in color parameters at $180{ }^{\circ} \mathrm{C}$, expressed as a function of $t$.

All parameters of the model functions and kinetics were estimated using a nonlinear iterative curve-fitting method. The coefficient of determination $\left(R^{2}\right)$ and the root mean-square error (RMSE) were used as criteria for the fitting of the tested models to the experimental data:

$R^{2}=\frac{\sum_{i=1}^{N}\left(\hat{Y}_{i}-\bar{Y}\right)^{2}}{\sum_{i=1}^{N}\left(Y_{i}-\bar{Y}_{i}\right)^{2}}$ 


\section{Keyaki wood}
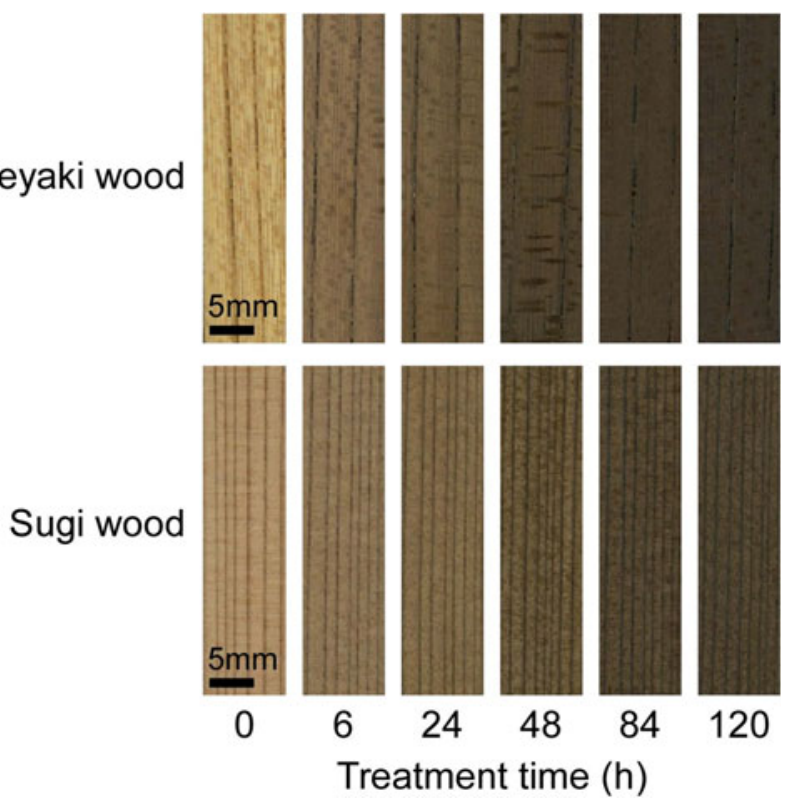

Fig. 1 Color changes of specimens treated at $180{ }^{\circ} \mathrm{C}$ in order of increasing treatment time
$\mathrm{RSME}=\sqrt{\frac{\sum_{i=1}^{N}\left(Y_{i}-\hat{Y}_{i}\right)}{N}}$,

where $\hat{Y}_{i}$ and $Y_{i}$ are the measured and modeled values, respectively, $\bar{Y}$ is the average of the measured data, and $N$ is the total number of observations. The higher the value of $R^{2}$ and the lower the value of RSME, the better did the model fit the data. The FlexPro 8 software package (Weisang $\mathrm{GmbH}$, Germany) was used for all data analysis.

\section{Results and discussion}

Color changes during heat treatment

Figure 1 shows the images of representative specimens. The specimens turned darker and browner with increased treatment time. The color changed uniformly from the outside to the middle of the specimens. Figures 2 and 3 show changes in $L^{*}, a^{*}, b^{*}$, and $\Delta E_{a b}^{*}$ of keyaki and sugi
Fig. 2 Changes in $L^{*}, a^{*}, b^{*}$, and $\Delta E_{a b}^{*}$ of keyaki wood during heat treatment as a function of time and temperature (error bar standard deviation)
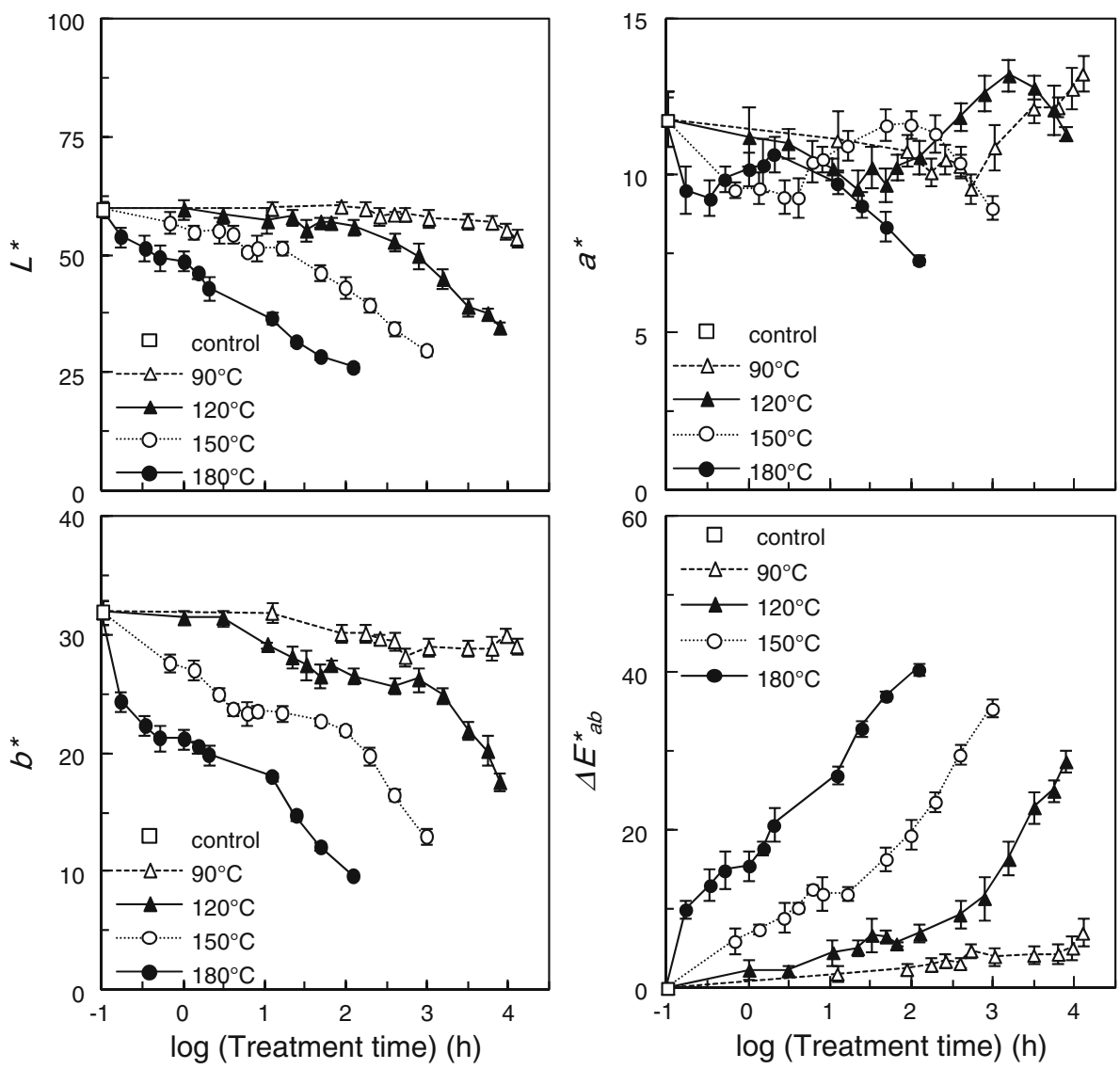
Fig. 3 Changes in $L^{*}, a^{*}, b^{*}$, and $\Delta E_{a b}^{*}$ of sugi wood during heat treatment as a function of time and temperature (error bar standard deviation)
Fig. 4 Changes in $a^{*}$ and $b^{*}$ of keyaki wood superposed using only horizontal shift factor $a_{T}$ (error bar standard deviation)
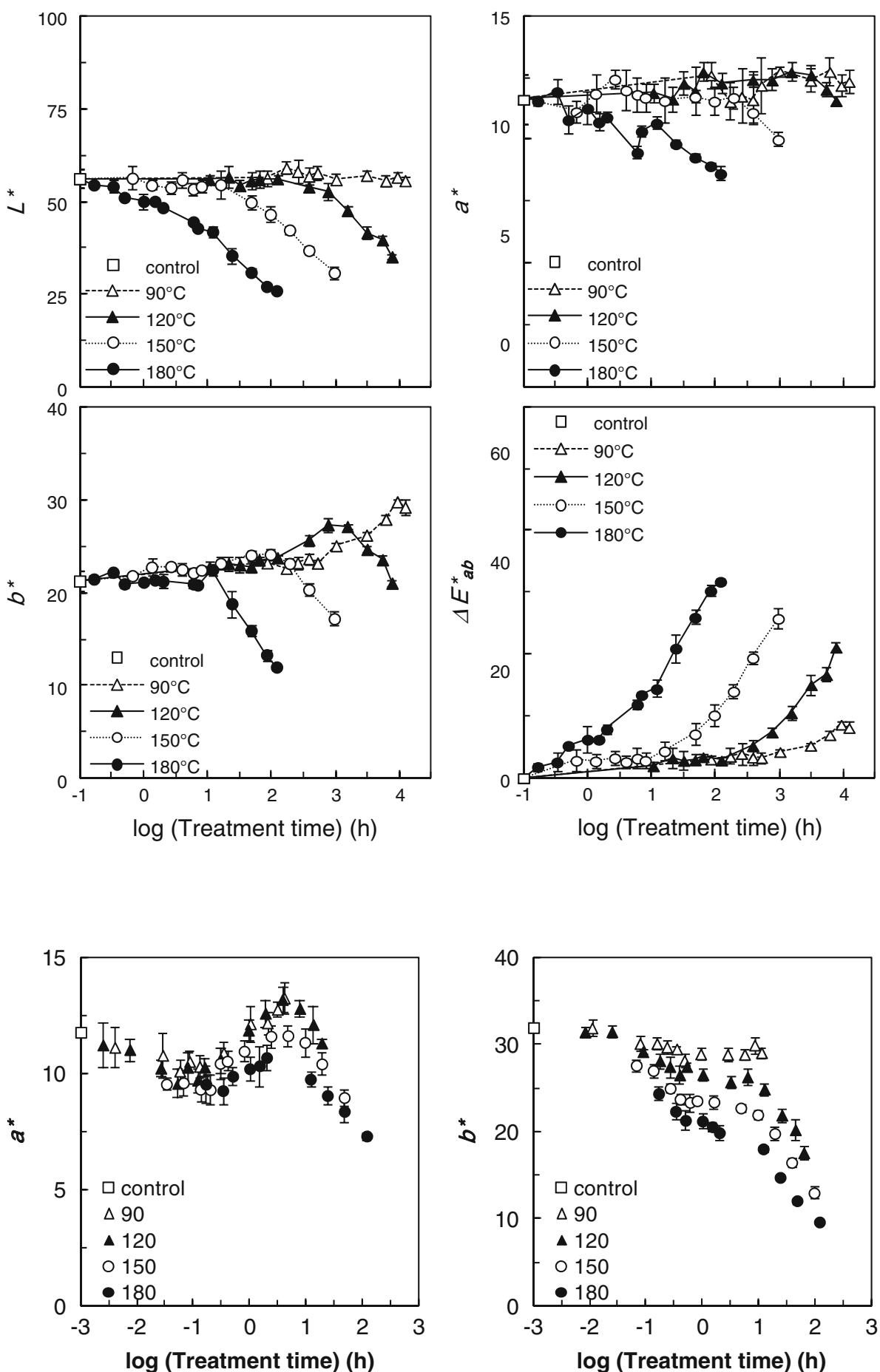

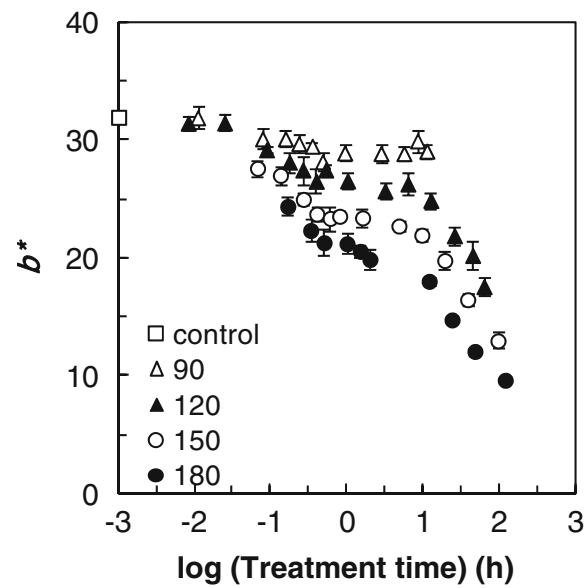

wood, respectively, according to the treatment time and temperature. The values of $L^{*}$ decreased in both keyaki and sugi wood, indicating that they became darker. This result corresponded to the increase in $\Delta E_{a b}^{*}$, which was largely dominated by decreasing $L^{*}$. Decreases in $L^{*}$ and increases in $\Delta E_{a b}^{*}$ during heat treatment have been well documented in various wood species [1-12]. In addition, changes in $a^{*}$ and $b^{*}$ differed depending on the wood species. In keyaki wood, the value of $a^{*}$ initially decreased, then increased to a peak and decreased again, whereas the value of $b^{*}$ decreased constantly with a shoulder. In sugi wood, the value of $a^{*}$ decreased slightly, whereas the value of $b^{*}$ initially increased and then decreased. This increase and subsequent decrease in $a^{*}$ and $b^{*}$ have been reported for 
some other wood species such as beech, spruce, and pine $[6,7,27]$, whereas a monotonous decrease in $a^{*}$ and $b^{*}$ has been reported for pine and eucalypt wood [3]. No significant change was previously reported in an analysis of sugi wood [28]. This inconsistency may be explained by the fact that treatment duration was insufficient in these reports.

Comparing the results among treatment temperatures in each species, changes in $L^{*}$ and $\Delta E_{a b}^{*}$ showed similar behavior irrespective of treatment temperature, whereas

Table 4 Coefficients of determination $\left(R^{2}\right)$ and root mean-square errors (RMSE) of regression curves using Eq. (9) for color changes of keyaki and sugi wood at $180{ }^{\circ} \mathrm{C}$

\begin{tabular}{llllll}
\hline & \multicolumn{2}{l}{ Keyaki wood } & & \multicolumn{2}{l}{ Sugi wood } \\
\cline { 2 - 3 } \cline { 5 - 6 } & $R^{2}$ & RMSE & & $R^{2}$ & RMSE \\
\hline$L^{*}$ & 0.9938 & 0.294 & 0.9962 & 0.634 \\
$a^{*}$ & 0.9957 & 0.721 & 0.9142 & 0.307 \\
$b^{*}$ & 0.9970 & 0.335 & 0.9740 & 0.542 \\
$\Delta E_{a b}^{*}$ & 0.9964 & 0.743 & 0.9967 & 0.614 \\
\hline
\end{tabular}

changes in $a^{*}$ and $b^{*}$ were temperature dependent. As shown in Figs. 2 and 3, the lower the treatment temperature, the higher the peak values of $a^{*}$ for keyaki and $b^{*}$ for sugi, indicating that treatment at lower temperatures enhanced the increase in these chromatic parameters. Furthermore, the lower the treatment temperature, the smaller the decreases in $b^{*}$ of keyaki and $a^{*}$ of sugi wood, indicating that heat treatment at lower temperatures moderated the reduction in these chromatic parameters. No such temperature dependencies were observed in hinoki wood and cellulose filter paper [12,13]. Thus, the results of our studies on heat treatment in several wood species at a wide range of durations and temperatures revealed that color changes in complex ways depending on the duration of heat treatment, temperature, and wood species. The results would contribute to the simple assessment of wood quality and understanding the empirical knowledge about quality changes. Almost all the main components of wood, i.e., cellulose, hemicelluloses, lignin, extractives, and ash contents are related to the color of wood and its changes [29]. Our previous study showed that cellulose is a major component that contributes to color changes of hinoki
Fig. 5 Changes in color parameters of keyaki wood: best-fit model [Eq. (9)] and superposed data using only horizontal shift factor $a_{T}$ for $L^{*}$ and $\Delta E_{a b}^{*}$ and using both $a_{T}$ and vertical shift factor $b_{T}$ for $a^{*}$ and $b^{*}$ (error bar standard deviation)
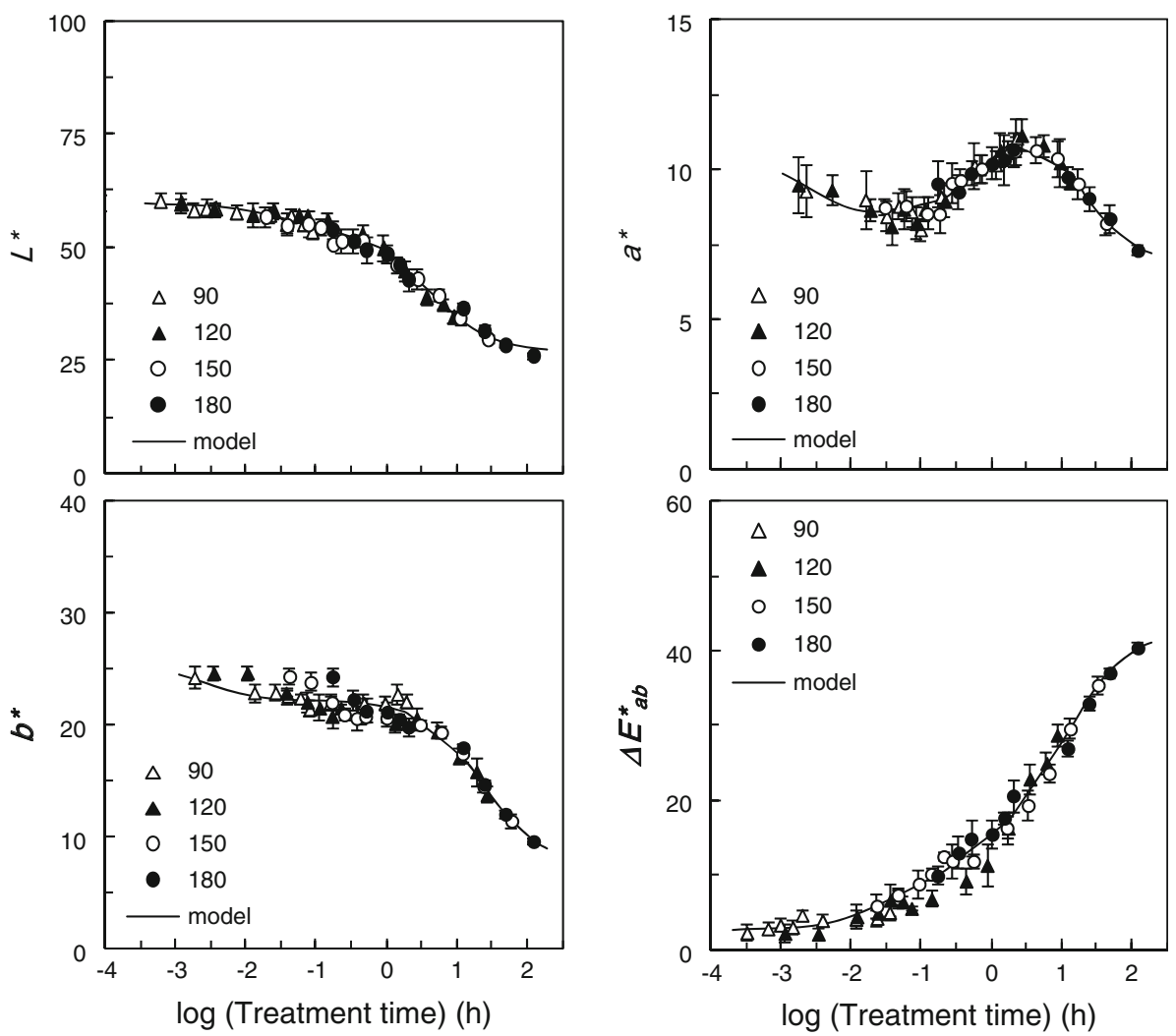
wood, while other components also have effects on color changes [13]. Extractives of each wood species also make the characteristic color [30-32] mainly expressed by chromatic parameters, $a^{*}$ and $b^{*}$. The different behavior of different color parameters would be caused by chemical changes of each component. However, CIELAB color parameters do not necessarily reflect a particular chemical change in wood. To refer to chemical changes, qualitative and quantitative analysis of different wavelength spectra and chemical components will be needed.

\section{Kinetic analysis}

In keyaki and sugi wood, changes in $L^{*}$ and $\Delta E_{a b}^{*}$ were analyzed using the TTSP method and by applying only the horizontal shift factor $a_{T}$. As shown in representative data for $a^{*}$ and $b^{*}$ in Fig. 4, single smooth superposed curves were not obtained for $a^{*}$ and $b^{*}$ by shifting only along the logarithmic time axis, though overlap of the inflection points of each curve was observed. This implies that application of the shift factor, $a_{T}$, only was insufficient for accurate prediction of color changes in keyaki and sugi wood and that temperature dependencies should also be considered. Therefore, the vertical shift factor $b_{T}$ was applied in addition to $a_{T}$ to analyze the changes in $a^{*}$ and $b^{*}$.
Based on the values of $R^{2}$ and RMSE, the following was selected as the best-fit function:

$P=\frac{C_{0}+C_{1} t+C_{2} t^{2}+C_{3} t^{3}}{1+C_{4} t+C_{5} t^{2}+C_{6} t^{3}}$,

where $C_{i}(i=0, \ldots, 6)$ is a constant. Note that this function was applied for numerical analysis of color changes; it may have no meaning in terms of the reaction mechanism.

Table 4 summarizes the values of $R^{2}$ and RMSE for Eq. (9) fitted to the data set of color changes at $180{ }^{\circ} \mathrm{C}$, indicating that Eq. (9) fitted well to the data set. Figures 5 and 6 show the well-superposed data with the regression curves of keyaki and sugi wood, respectively, using only $a_{T}$ for $L^{*}$ and $\Delta E_{a b}^{*}$ and both $a_{T}$ and $b_{T}$ for $a^{*}$ and $b^{*}$. Figure 7 shows the Arrhenius plots for $L^{*}$ of keyaki wood as an example. The regression lines of the Arrhenius plots for all color parameters showed good linearity $\left(R^{2}>0.980\right)$, suggesting that color changes at $90-180{ }^{\circ} \mathrm{C}$ were caused by an apparently similar reaction. The apparent activation energies $\left(E_{\mathrm{a}}\right)$ calculated from each color parameter were higher than those of hinoki wood and cellulose filter paper $[12,13]$, particularly for $L^{*}$ and $\Delta E_{a b}^{*}$ (Table 5). This result indicated that color change reactions of keyaki and sugi wood apparently have higher energy barriers than those of hinoki wood and cellulose. Considering sugi and hinoki are
Fig. 6 Changes in color parameters of sugi wood: bestfit model [Eq. (9)] and superposed data using only horizontal shift factor $a_{T}$ for $L^{*}$ and $\Delta E_{a b}^{*}$ and using both $a_{T}$ and vertical shift factor $b_{T}$ for $a^{*}$ and $b^{*}$ (error bar standard deviation)
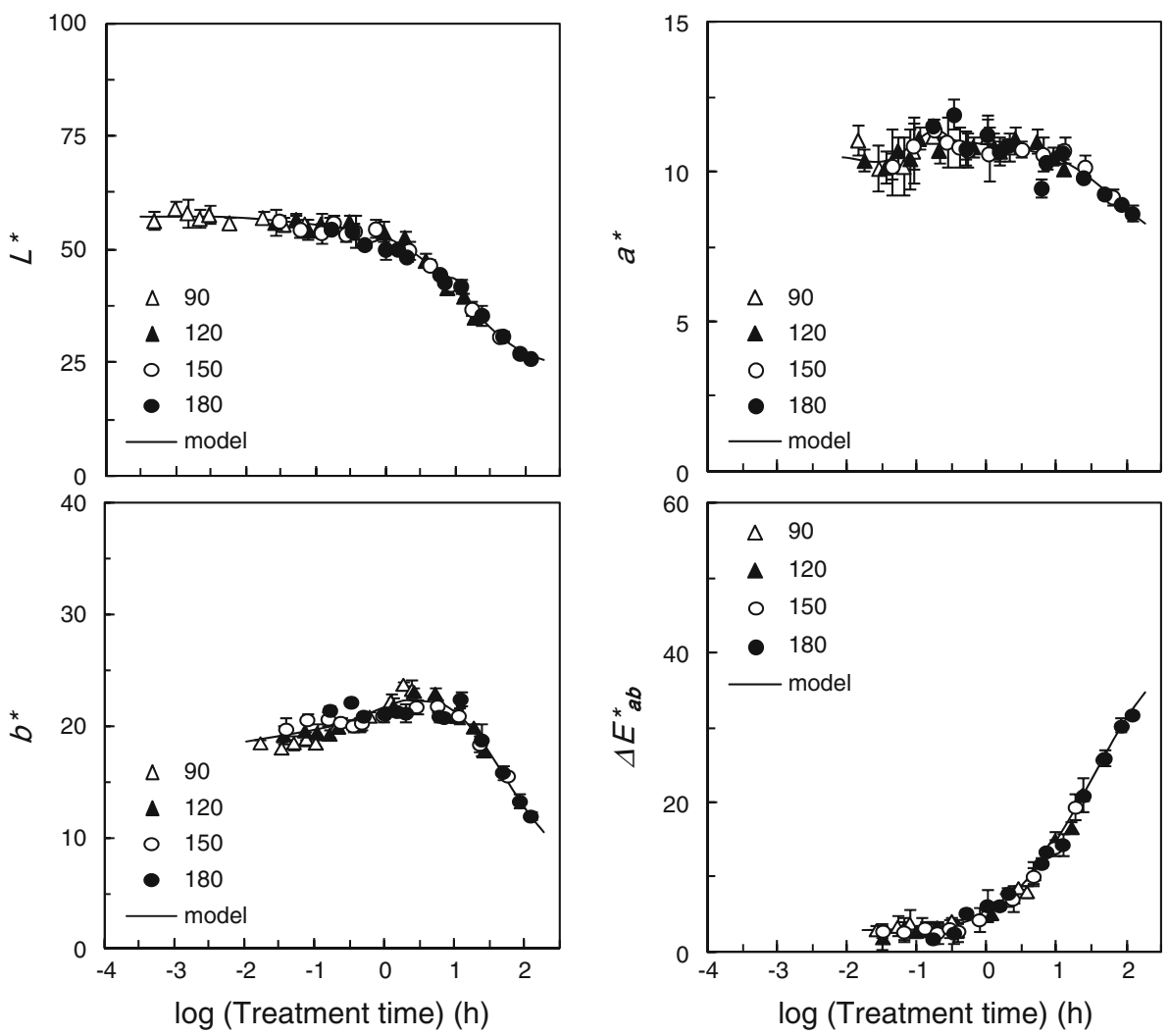
softwoods and keyaki is hardwood, the present results differ from those of previous studies, which suggested that the thermal degradation of hardwood proceeds faster than that of softwood because some components of hardwood are more reactive than those of softwood [33, 34]. The differences in $E_{\mathrm{a}}$ values among color parameters may therefore be interpreted as differences in reactivity of the chemical components responsible for each color parameter.

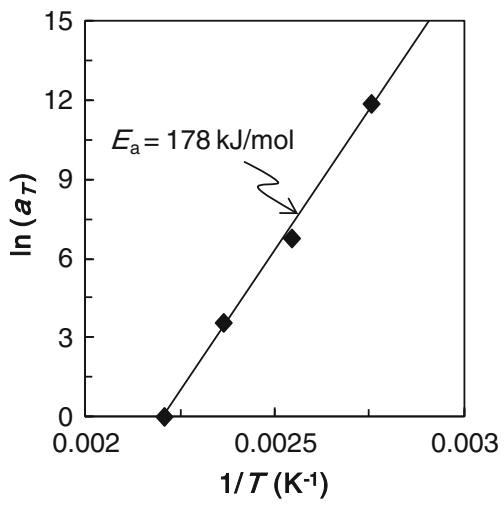

Fig. 7 Arrhenius plots for $L^{*}$ of keyaki wood, regression line $\left(R^{2}=0.997\right)$, and calculated apparent activation energy $\left(E_{\mathrm{a}}\right)$

Table 5 Comparison of apparent activation energies $\left(E_{\mathrm{a}}\right)$ calculated using the modified Arrhenius equation [Eq. (5)] among several wood species [12] and cellulose filter paper [13]

\begin{tabular}{|c|c|c|c|c|}
\hline & \multicolumn{4}{|c|}{$E_{\mathrm{a}}(\mathrm{kJ} / \mathrm{mol})$} \\
\hline & $\begin{array}{l}\text { Keyaki } \\
\text { wood }\end{array}$ & $\begin{array}{l}\text { Sugi } \\
\text { wood }\end{array}$ & $\begin{array}{l}\text { Hinoki } \\
\text { wood [12] }\end{array}$ & $\begin{array}{l}\text { Cellulose filter } \\
\text { paper [13] }\end{array}$ \\
\hline$L^{*}$ & 178 & 180 & 117 & 125 \\
\hline$a^{*}$ & $132^{\mathrm{a}}$ & $135^{\mathrm{a}}$ & 95 & 124 \\
\hline$b^{*}$ & $133^{\mathrm{a}}$ & $129^{\mathrm{a}}$ & 114 & 118 \\
\hline$\Delta E_{a b}^{*}$ & 188 & 123 & 113 & 120 \\
\hline
\end{tabular}

${ }^{a}$ Values of $E_{\mathrm{a}}$ were calculated by applying both $a_{T}$ and $b_{T}$ for $a^{*}$ and $b^{*}$ of keyaki and sugi wood
These results implied that reactivity may differ according to species and physical properties. However, further investigations including chemical analysis are needed to elucidate the $E_{\mathrm{a}}$ values obtained in this study.

The relationships between $b_{T}$ and treatment temperature for $a^{*}$ and $b^{*}$ are shown in Fig. 8. As the reference temperature was $180{ }^{\circ} \mathrm{C}, b_{T}$ at $180^{\circ} \mathrm{C}$ was 1.0 . The values of $b_{T}$ represent the difference in the extent of decrease or increase in $a^{*}$ or $b^{*}$ between treatment at $180{ }^{\circ} \mathrm{C}$ and that at other temperatures. The values of $b_{T}$ decreased with increasing temperature toward 1.0 at $180{ }^{\circ} \mathrm{C}$ in both $a^{*}$ and $b^{*}$. In Figs. 2, 3, and 8, specimens were more reddish and yellowish at lower temperatures and $b_{T}$ expressed its degree. The relationship between $b_{T}$ and temperature was linear from 120 to $180{ }^{\circ} \mathrm{C}$, but $b_{T}$ seemed to be saturated at temperatures less than $120^{\circ} \mathrm{C}$. This result indicates that treatment at lower temperatures keep colorimetric parameters larger and it may have an upper limit. Studies examining color changes at lower temperatures than those used in this experiment will allow further evaluation of $b_{T}$.

In the present study, the factors affecting temperature dependency expressed by $E_{\mathrm{a}}$ and $b_{T}$ of color changes in keyaki and sugi wood could not be determined. However, the temperature dependency may have been due to the extractives responsible for the characteristic color of wood, which are usually expressed as chromatic parameters such as $a^{*}$ and $b^{*}$ [29]. Characteristic extractives possibly give different $E_{\mathrm{a}}$ to different wood species and to different color parameters such as $L^{*}, a^{*}, b^{*}$, and $\Delta E_{a b}^{*}$.

From the results of this study, we can conclude that color changes in keyaki and sugi wood during heat treatment can be successfully analyzed using a kinetic approach combined with the TTSP method. This strategy allows prediction of color changes at any of the temperatures and durations used in the present study using $E_{\mathrm{a}}$ and $a_{T}$. Temperature dependencies expressed by $b_{T}$ must be considered when needed.
Fig. 8 Relationship between vertical shift factor $b_{T}$ and treatment temperature for $a^{*}$ and $b^{*}$. a Keyaki wood and b sugi wood
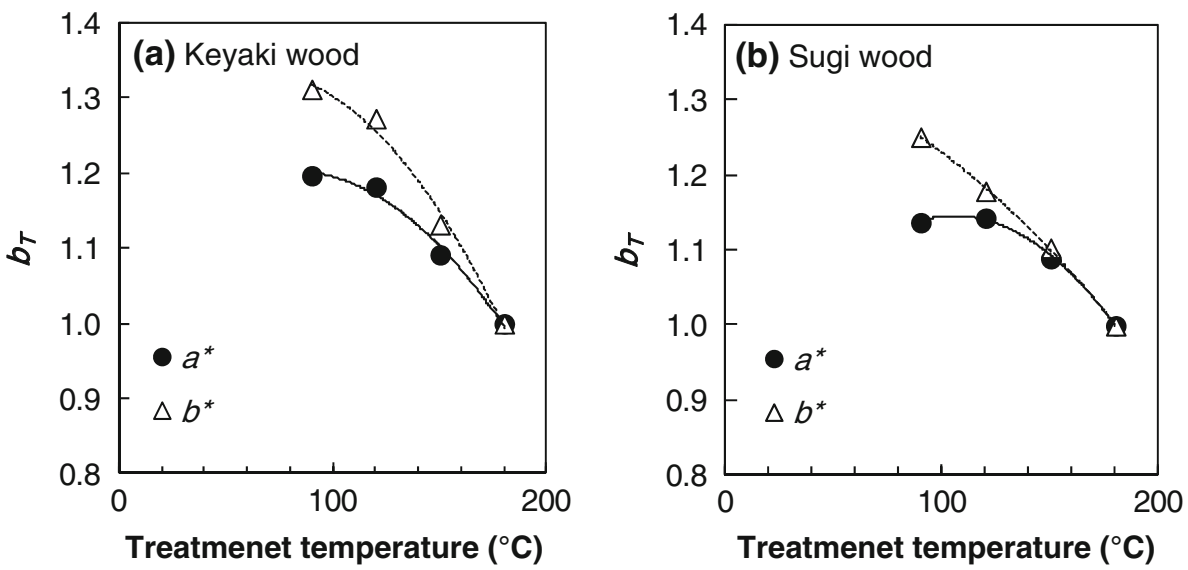


\section{Conclusions}

Color changes in keyaki and sugi wood during heat treatment at $90-180{ }^{\circ} \mathrm{C}$ were investigated in this study. The values of $L^{*}$ and $\Delta E_{a b}^{*}$ decreased and increased, respectively, in both wood species at all treatment temperatures, whereas the values of $a^{*}$ and $b^{*}$ showed species- and temperature-dependent behaviors. Kinetic analysis was successfully applied to describe these color changes. Calculating the values of apparent activation energy and shift factors for time-temperature superposition allowed prediction of color changes in the present experimental conditions. The present study revealed and quantitatively evaluated differences in color change behavior between species and temperatures. The results provide a more comprehensive understanding of color changes in wood as a function of time and temperature.

Acknowledgments This work was supported by Grants-in-Aid for Scientific Research (A) (No. 20248020) and for JSPS Fellows (No. 21.2994). The authors thank Dr. Masashi Nakamura for his help with the spectroscopic imaging system and his critical reading of the manuscript.

\section{References}

1. Esteves B, Pereira H (2009) Wood modification by heat treatment: a review. BioRes 4:370-404

2. Navi P, Sandberg D (2012) Thermo-hydro-mechanical processing of wood. EPFL Press, Lausanne, pp 7-15

3. Esteves B, Marques AV, Domingos I, Pereira H (2008) Heatinduced colour changes of pine (Pinus pinaster) and eucalypt (Eucalyptus globulus) wood. Wood Sci Technol 42:369-384

4. Möttönen V, Kärki T (2008) Color changes of birch wood during high-temperature drying. Drying Technol 26:1125-1128

5. Sundqvist B (2002) Color response of Scots pine (Pinus sylvestris), Norway spruce (Picea abies) and birch (Betula pubescens) subjected to heat treatment in capillary phase. Eur J Wood Wood Prod 60:106-114

6. Bekhta P, Niemz P (2003) Effect of high temperature on the change in color, dimensional stability and mechanical properties of spruce wood. Holzforschung 57:539-546

7. Brischke C, Welzbacher CR, Brandt K, Rapp AO (2007) Quality control of thermally modified timber: interrelationship between heat treatment intensities and CIE $L^{*} a^{*} b^{*}$ color data on homogenized wood samples. Holzforschung 61:19-22

8. González-Peña MM, Hale MDC (2009) Colour in thermally modified wood of beech, Norway spruce and Scots pine. Part 2: property predictions from colour changes. Holzforschung 63:394-401

9. Johansson D, Morén T (2006) The potential of colour measurement for strength prediction of thermally treated wood. Holz Roh Werkst 64:104-110

10. Del Menezzi CHS, Tomaselli I, Okino EYA, Teixeira DE, Santana MAE (2009) Thermal modification of consolidated oriented strandboards: effects on dimensional stability, mechanical properties, chemical composition and surface color. Eur J Wood Prod 67:383-396

11. González-Peña MM, Hale MD (2011) Rapid assessment of physical properties and chemical composition of thermally modified wood by mid-infrared spectroscopy. Wood Sci Technol 45:83-102

12. Matsuo M, Yokoyama M, Umemura K, Gril J, Yano K, Kawai S (2010) Color changes in wood during heating: kinetic analysis by applying a time-temperature superposition method. Appl Phys A 99:1-6

13. Matsuo M, Umemura K, Kawai S (2012) Kinetic analysis of color changes in cellulose during heat treatment. J Wood Sci 58:113-119

14. Matsuo M, Yokoyama M, Umemura K, Sugiyama J, Kawai S, Gril J, Kubodera S, Mitsutani T, Ozaki H, Sakamoto M (2011) Aging of wood: analysis of color changes during natural aging and heat treatment. Holzforschung 65:361-368

15. Stamm AJ (1956) Thermal degradation of wood and cellulose. Ind Eng Chem 48:413-417

16. Japanese Industrial Standard Committee (2008) JIS Z 8729 Colour specification-CIELAB and CIELUV colour spaces

17. Japanese Industrial Standard Committee (2009) JIS Z 8730, Colour specification-colour differences of object colours

18. Atkins P, Paula J (2010) Atkins' physical chemistry, 9th edn. Oxford University Press, New York, pp 782-830

19. Ding HZ, Wang ZD (2007) Time-temperature superposition method for predicting the permanence of paper by extrapolating accelerated ageing data to ambient conditions. Cellulose 14:171-181

20. Gillen KT, Clough RL (1989) Time-temperature-dose rate superposition: a methodology for extrapolating accelerated radiation aging data to low-dose rate conditions. Polym Degrad Stabil 24:137-168

21. Wise J, Gillen KT, Clough RL (1995) An ultrasensitive technique for testing the Arrhenius extrapolation assumption for thermally aged elastomers. Polym Degrad Stabil 49:403-418

22. Gillen KT, Celina M (2001) The wear-out approach for predicting the remaining lifetime of materials. Polym Degrad Stabil 71:15-30

23. Ding HZ, Wang ZD (2008) On the degradation evolution equations of cellulose. Cellulose 15:205-224

24. Ferry JD (1980) Viscoelastic properties of polymers, 3rd edn. Willy, New York, pp 264-320

25. Miyano Y, Nakada M, Kasamori M, Muki R (2000) Effect of physical aging on the creep deformation of an epoxy resin. Mech Time Depend Mater 4:9-20

26. Nagamatsu K, Takemura T, Yoshitomi T, Takemoto T (1958) Effect of crystallinity on the viscoelastic properties of polyethylene. J Polym Sci 33:515-518

27. González-Peña MM, Hale MDC (2009) Colour in thermally modified wood of beech, Norway spruce and Scots pine. Part 1: colour evolution and colour changes. Holzforschung 63:385-393

28. Okuyama T, Yamamoto H, Kobayashi I (1990) Quality improvement in small log of Sugi by direct heating method (2) (in Japanese). Mokuzai Kogyo 45:63-67

29. Hon DNS, Mineura N (2001) Color and discoloration. In: Hon DNS, Shiraishi N (eds) Wood and cellulosic chemistry, 2nd edn. Mercel Dekker, New York, pp 385-442

30. Ohashi H, Hayashi H, Yamada M, Yasue M (1987) Phenolic heartwood constituents and heartwood color of Japanese cypress (in Japanese). Res Bull Fac Agric Gifu Univ 52:131-139

31. Funaoka K, Tanaka M (1957) Studies on flavonoids of the wood of Zelkova serrata Makino. VII (in Japanese). Mokuzai Gakkaishi 3:173-176

32. Takahashi K (1981) Heartwood phenols and their significance to color in Cryptomeria japonica D. Don. Mokuzai Gakkaishi 27:654-657

33. Kohara J (1958) Study on the old timber (in Japanese). Ind Eng Chiba Univ 9(15):1-55

34. Kohara J (1958) Study on the old timber (in Japanese). Ind Eng Chiba Univ 9(16):23-65 